\title{
Probabilistic earthquake early warning times in Fujian Province
}

\author{
Hongcai Zhang $\cdot$ Xing Jin
}

Received: 16 July 2012/ Accepted: 10 January 2013/Published online: 16 November 2013

(C) The Seismological Society of China, Institute of Geophysics, China Earthquake Administration, and Springer-Verlag Berlin Heidelberg 2013

\begin{abstract}
Earthquake early warning (EEW) systems are a new and effective way to mitigate the damage associated with earthquakes. A prototype EEW system is currently being constructed in the Fujian Province, a region along the Southeast coast of China. It is anticipated that the system will be completed in time to be tested at the end of this year (2013). In order to evaluate how much advanced warning the EEW system will be able to provide different cities in Fujian, we established an EEW information release scheme based on the seismic monitoring stations distributed in the region. Based on this scheme, we selected 71 historical earthquakes. We then obtained the delineation of the region's potential seismic source data in order to estimate the highest potential seismic intensities for each city as well as the EEW system warning times. For most of the Fujian Province, EEW alarms would sound several seconds prior to the arrival of the destructive wave. This window of time gives city inhabitants the opportunity to take protective measures before the full intensity of the earthquake strikes.
\end{abstract}

Keywords Earthquake early warning systems .

Lead time $\cdot$ Fujian region

\section{Introduction}

Earthquake early warning (EEW) systems were first proposed by Cooper (1968) of the Caltech in a San Francisco

H. Zhang $(\bowtie) \cdot X$. Jin

Fujian Earthquake Administration, Fuzhou 350003, China

e-mail: zhanghongcai521@163.com

H. Zhang $\cdot$ X. Jin

Institute of Earthquake Mechanic, China Earthquake

Administration, Harbin 350003, China
Daily Evening Bulletin after the magnitude 6.81868 Hayward earthquake. Cooper's system was based on a simple physical principle: electromagnetic waves travel much faster than seismic waves $(\sim 300,000 \mathrm{~km} / \mathrm{s}$ vs. only a few $\mathrm{km} / \mathrm{s}$ ). As a result, if a real-time rapid detection system were to be placed next to a seismically active region, an alert could be electromagnetically transmitted to the surrounding regions before the arrival of the destructive $S$ and surface waves. With the advent of modern computers, seismic networks, and communication technology, EEW systems have become a feasible means for the seismic monitoring community to prepare the public for impending quakes. Over the last two decades, several EEW systems, or rapid response systems, were installed. As a result, many tectonically active regions, including Japan, Mexico, Italy, Taiwan, California, etc., have some form of EEW system either in operation or currently under development (Kamigaichi 2004; Kamigaichi et al. 2009; Allen et al. 2007; Gilead et al. 2007; Iglesias et al. 2007; Wu and Teng 2002; Erdik et al. 2003; Zollo et al. 2004, 2009; Hsiao et al. 2009; Horiuchi et al. 2005). These systems play an integral role in mitigating the aftermath of major earthquakes. For example, during the 2011 Tohoku earthquake, Japan's EEW system promptly issued 71 warnings, as of March 31, 2011, to the general public. The information helped prevent earthquake-related deaths by giving citizens the time to take emergency protective measures.

Because the effectiveness of EEW's is based largely on their ability to relay warnings as quickly as possible, EEW systems should make rapid judgments of earthquake location and magnitude, etc. Unfortunately, EEW's are limited by the amount of information that the system can process. It is, therefore, extremely challenging for EEW's to acquire accurate estimations as rapidly as possible. As a result, effective EEW systems are forced to maximize the balance 


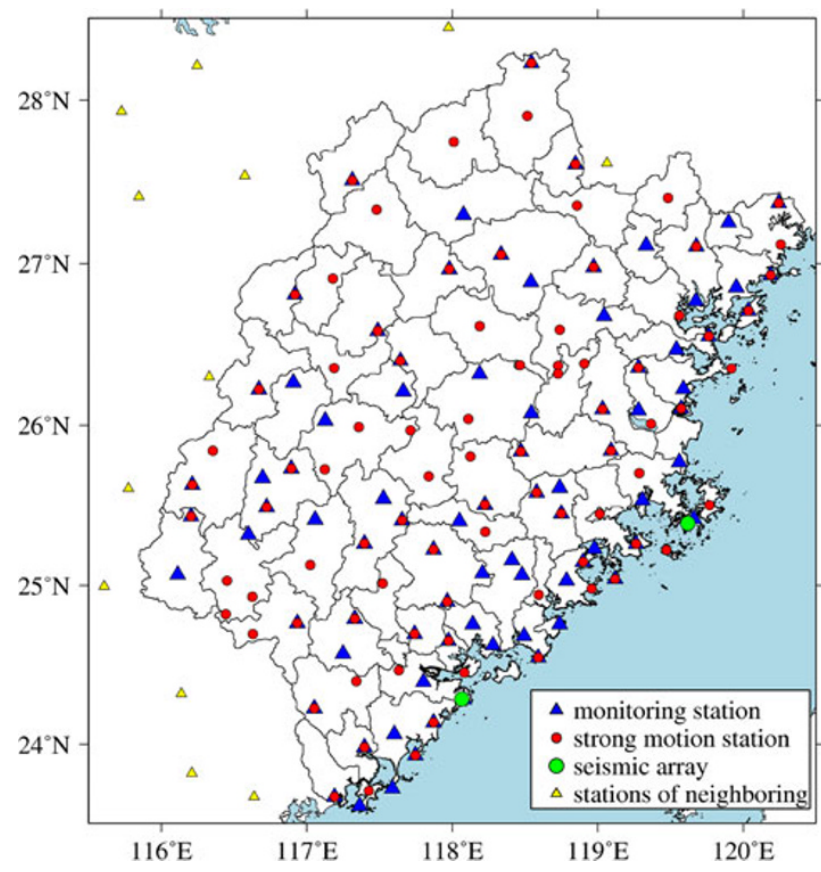

Fig. 1 Distribution of seismic monitoring stations in the Fujian Province

between processing speed (to save time) and the reliability of the information (to improve the accuracy).

Fujian Province, in Southeastern China, is one of the most economically important areas in China. Historically, several destructive earthquakes have occurred in this region and in nearby-Taiwan making this area one of the most earthquake-prone in China. After the 2008 Wenchuan earthquake, China increased its emphasis on earthquake hazard prevention. This sparked the construction of a prototype EEW system in the Fujian region in 2009, which will be completed at the end of this year (2013). Once the system is complete, it will be tested on-line in real time. In this paper, we test the effectiveness of the system by evaluating the potential early warning times for different parts of the Fujian Province.

\section{Seismic monitoring networks in the Fujian Province}

The Fujian Province seismic monitoring network has been expanding since 1985. In the first few years, there were only five monitoring stations, one relay station and one processing center. In the following 13 years, 17 seismograph stations were built. From 1999 to 2001, seven seismograph stations and five strong motion stations were added to the network. During the "10th Five-Year Plan" period, 12 monitoring stations were completed, and the total number of seismograph stations reached 41 . These stations transmit the ground motion monitoring data to real-time processing centers via SDH lines provided by
China Telecom. During the "11th Five-Year Plan" period, station numbers increased dramatically with 44 real-time transmission broadband seismograph stations, 84 real-time transmission strong motion stations (44 of which share sites with broadband seismograph stations), and two seismic arrays. The two seismic arrays, each have 16 sub-stations, have completed construction the year before last and have put into operation in the middle of 2012 when the equipment is completely installed and commissioned. Monitoring data from these stations is also transmitted in real-time to the processing center via China Telecom SDH lines. Today, the region has a total of 125 independent monitoring stations, two seismic arrays, and 156 seismic sensors with an average distance of $26 \mathrm{~km}$ between stations (Fig. 1).

Each station is comprised of a seismometer, a data collector, a GPS device, power supply equipment, lightning protection equipment, and a data transmission device. In total, there are 46 CMG-3ESPC-120 seismometers, 16 CMG-3ESPC-60 seismometers, 14 FSS-3M seismometers, 5 BBVS-60 seismometers, 1 FSS-3B seismometer, 1 CTS1 seismometer, and 84 SLJ-100 strong motion seismometers. 40 of the strong ground motion stations are equipped with an EDAS-24GN-3 data collector, 41 of the seismic stations have an EDAS-24IP-3 data collector, and 44 stations have both an acceleration meter and a velocity meter, as well as an EDAS-24GN-6 data collector.

\section{The early warning publication scheme}

This paper focuses on the region within the Fuijan Province from $\mathrm{N} 23^{\circ} 33^{\prime}$ to $\mathrm{N} 28^{\circ} 19^{\prime}, \mathrm{E} 115^{\circ} 50^{\prime}$ to $\mathrm{E} 120^{\circ} 43^{\prime}$. Based on previous studies, we first assume that $\mathrm{P}$ wave spread at a speed of $6.0 \mathrm{~km} / \mathrm{s}$, that peak ground motion acceleration (PGA) is $3.3 \mathrm{~km} / \mathrm{s}$, and that peak ground motion displacement (PGD) is $3.0 \mathrm{~km} / \mathrm{s}$ (Fan et al. 1990). We then divide the research area into equal intervals of $0.02 \times 0.02^{\prime \prime}$, resulting in a total of 27,300 nodes. If we then suppose that an earthquake (with focal depth set to $10 \mathrm{~km}$ ) (Lin et al. 2010) happens at each node, we can analyze the time required to trigger a given station and to record observations of PGA/PGD at each station, etc. In order to issue EEW information as quickly and as reliably as possible, we set the following guidelines for early warning publication: when the PGD arrival is observed at just one station, the first report is released; when the arrival is noted at a second station, the results are renewed and republished. Only when data is available from three or more stations, is the warning information most accurate. In this paper, we focus on the first three reports, making a statistical analysis of the time needed to produce these reports.

Figure 2 and Tables 1 and 2 show (1) the statistical result of the time needed to trigger a station, (2) the PGA 

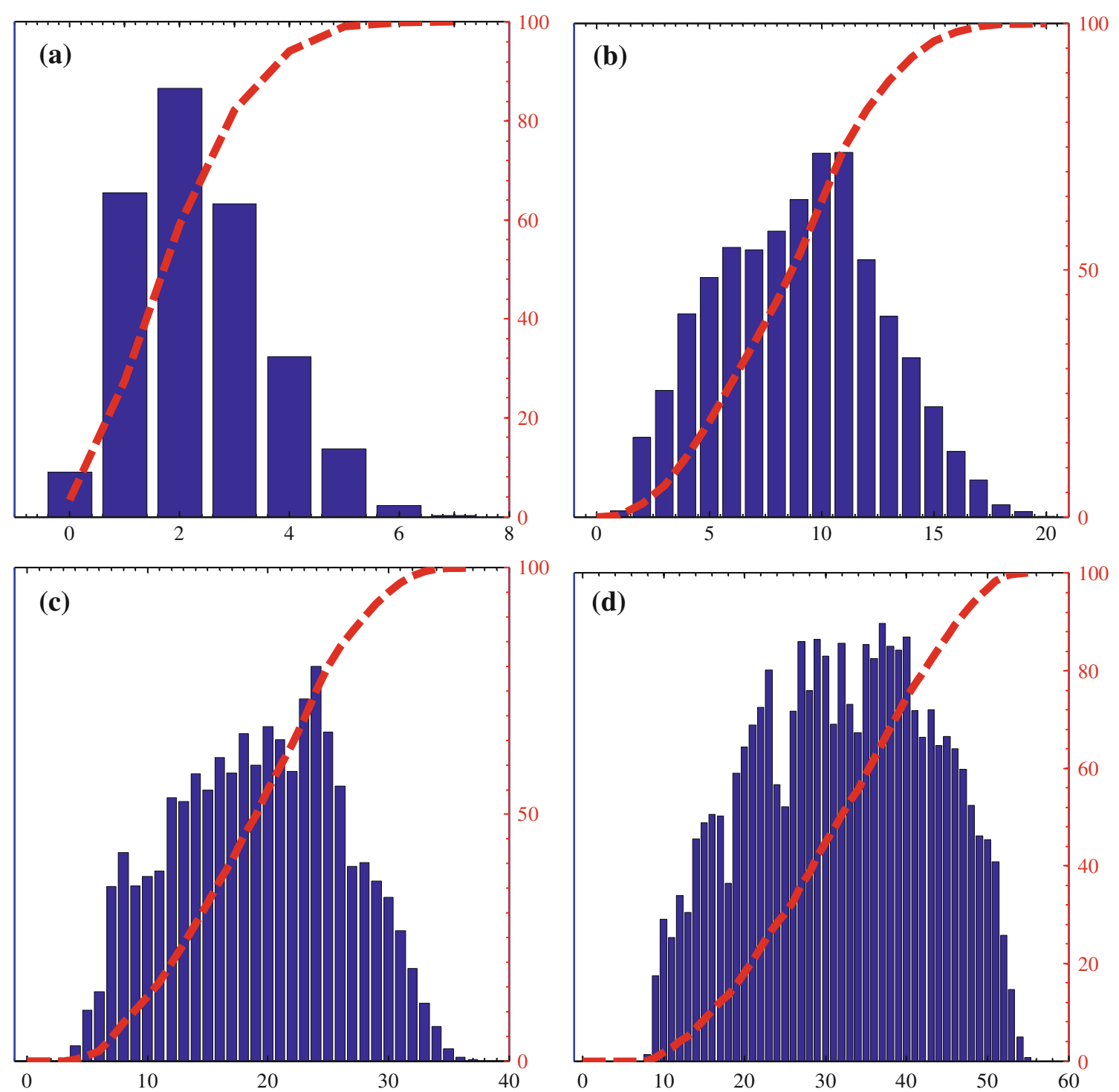

Fig. 2 Histograms and cumulative percentage curves of the stations triggered after an earthquake occurs (a-d have time windows of 5, 10, 15, and $20 \mathrm{~s}$, respectively.)

Table 1 Station number statistics pertaining to information received post-earthquakes

\begin{tabular}{lllrrrr}
\hline & \multicolumn{7}{l}{ Time since earthquake occurs (s) } \\
\cline { 2 - 7 } & 5 & 10 & 15 & 20 & 25 & 30 \\
\hline Trigger & & & & & & \\
Mean & 2.4 & 9.0 & 19.2 & 32.0 & 46.6 & 62.6 \\
$95 \%$ & 1.0 & 3.0 & 8.0 & 13.0 & 21.0 & 33.0 \\
PGA arrival & & & & & & \\
Mean & 0.7 & 2.8 & 6.2 & 10.8 & 16.4 & 22.8 \\
$95 \%$ & 0 & 1.0 & 2.0 & 4.0 & 7.0 & 9.0 \\
PGD arrival & & & & & & \\
Mean & 0.6 & 2.4 & 5.2 & 9.0 & 13.8 & 19.2 \\
$95 \%$ & 0 & 1.0 & 2.0 & 3.0 & 5.0 & 8.0 \\
\hline
\end{tabular}

Table 2 Station number statistics after the first station is triggered

\begin{tabular}{lrrrrrr}
\hline & \multicolumn{6}{c}{ Time since the first station triggered (s) } \\
\cline { 2 - 7 } & 5 & 10 & 15 & 20 & 25 & 30 \\
\hline Trigger & & & & & & \\
Mean & 5.3 & 13.9 & 25.6 & 39.2 & 55.0 & 71.4 \\
$95 \%$ & 2.0 & 6.0 & 12.0 & 18.0 & 29.0 & 42.0 \\
PGA arrival & & & & & & \\
Mean & 1.7 & 4.4 & 8.4 & 13.6 & 19.6 & 26.4 \\
$95 \%$ & 1.0 & 2.0 & 3.0 & 6.0 & 8.0 & 12.0 \\
PGD arrival & & & & & & \\
Mean & 1.4 & 3.7 & 7.0 & 11.3 & 16.4 & 22.3 \\
$95 \%$ & 1.0 & 1.0 & 3.0 & 4.0 & 7.0 & 9.0 \\
\hline
\end{tabular}



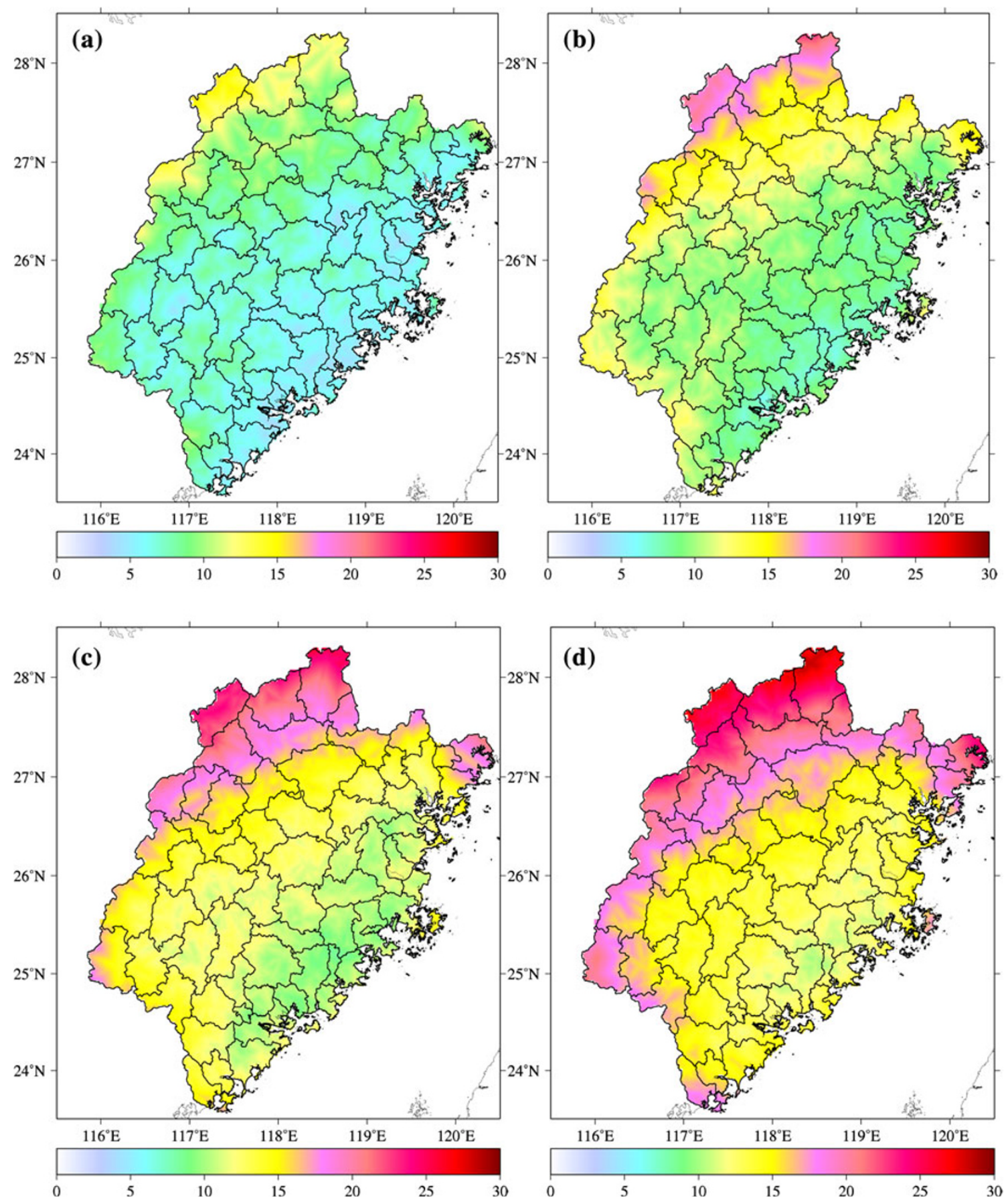

Fig. 3 Contour maps showing station triggering times (a-d are the times needed to trigger 5, 10, 15, and 20 stations, respectively.)

and PGD arrival times at stations when the earthquake occurs, and (3) when the first station is triggered. These results show that in the Fujian Province, an average of 2.4 stations will be triggered after the first $5 \mathrm{~s}$ (1.0 station at $95 \%$ probability), that 0.7 stations will have PGA records, and that 0.6 stations will have PGD records. Within the next $5 \mathrm{~s}$, another $\sim 6.6$ stations will be triggered $(2.0$ stations at $95 \%$ probability), 2.8 stations will have PGA records, and 2.4 stations will have PGD records. At $20 \mathrm{~s}$, 32.0 stations will be triggered (13.0 stations at $95 \%$ probability), and 10.8 stations and 9.0 stations will have PGA and PGD records, respectively. When we begin the statistical analyses only after the first station is triggered, the results differ slightly. $5 \mathrm{~s}$ after the first station is triggered, an average of 5.3 stations will be triggered (2.0 stations at $95 \%$ probability); 1.7 stations will have 
recorded PGA, while 1.4 stations will have recorded PGD. Ten seconds later, an average of 13.9 stations will be triggered (6.0 stations at $95 \%$ probability), 4.4 stations will have records of PGA, and 3.7 stations will have records of PGD. Twenty seconds later, an average of 39.2 stations will be triggered (18.0 stations at $95 \%$ probability), and 13.6 and 11.3 stations will have records of PGA and PGD, respectively. The only difference between these two statistical results is the selection of the start time. Other statistical results can easily be obtained from the above tables, and as a result, we will not repeat them here (Fig. 3).

Based on the above statistics and following the information release guidelines previously described, we propose the following EEW schemes for the Fujian Province. For the first report to be issued, at least 3 stations must be triggered and at least 1 station must have a PGD record in order to calculate the magnitude of the earthquake (" $3+1$ Scheme"). When 4 stations are triggered and 1 station has a PGD record (" $4+1$ Scheme"), the information from the first report has a $95 \%$ probability guarantee. Similarly, for the second and third reports, 7 stations must be triggered and two stations must have PGD records ("7 +2 Scheme") and 10 stations must triggered and 3 stations must have PGD records $(10+3$ Scheme), respectively. In order to ensure probabilities above $95 \%$, however, stations would require schemes of $8+2$ and $12+3$ for the second and third reports, respectively (Table 3 ).

Figure 4 and Table 4 outline the distribution of early warning release times needed for the first three reports in the Fujian Province. After the earthquake, the first report is published within an average of $6.37 \mathrm{~s}$ if the " $3+1$ Scheme" is used and $7.01 \mathrm{~s}$ if the " $4+1$ Scheme" is used. For most parts of the Fujian Province, the first early warning information is published $10.12 \mathrm{~s}$ after an earthquake occurs using the " $3+1$ Scheme" (11.84 s for " $4+1$ Scheme"; see Table 4 for more detail). The information release times vary slightly in different regions of the Fujian Province. As can be seen from Fig. 4, coastal areas, which have a much higher density of seismometers, have shorter early warning release times.

\section{Potential EEW release times for Fujian Province cities}

In this paper, we analyzed the data from 71 historical earthquakes $(M>4.0)$ and delineated the potential seismic source data from the Fujian Province to evaluate potential EEW times for different cities. Information on the highest seismic intensity that each city is likely to experience can be estimated through the
Table 3 EEW information publish scheme

\begin{tabular}{llll}
\hline & Triggering & PGD arrival & Scheme name \\
\hline $\begin{array}{llll}\text { First report } \\
\text { Mean }\end{array}$ & 3 & 1 & $3+1$ \\
$95 \%$ & 4 & 1 & $4+1$ \\
Second report & & & \\
Mean & 7 & 2 & $7+2$ \\
$95 \%$ & 8 & 2 & $8+2$ \\
Third report & & 3 & $10+3$ \\
Mean & 10 & 3 & $12+3$ \\
$95 \%$ & 12 & & \\
\hline
\end{tabular}

intensity attenuation relationships obtained by previous researchers. As is shown in Fig. 5, the scope of the evaluation is restricted to the $100 \mathrm{~km}$ immediately surrounding the Fujian Province. Red circles represent the location of the 71 historical earthquakes, with circle sizes reflecting earthquake magnitudes; rectangles represent different delineations of the potential seismic source area with different colors representing the different upper magnitudes for each of the source areas. The seismic risk is much higher in Southern Fujian than in the rest of the Province. The 1604 Quanzhou earthquake, which occurred off shore, was the largest earthquake to occur in the Province. Fortunately, the density of seismic stations in this region is also higher than in other regions. As a result, it is possible to make rapid estimations of earthquake parameters based on the data from these stations.

In order to estimate earthquake parameters based on the historical earthquake data, each potential seismic source area is first divided into equal intervals of $0.02^{\prime \prime}$, each grid node is then taken to be the epicenter of an earthquake. Earthquake warning release times are dependent on the relative location of seismic stations and their ability to detect $\mathrm{P}$ wave arrivals and to release the warning information to general public. According to the previously mentioned information release schemes, in order to confirm an earthquake event, at least one station must have calculated the earthquake's magnitude and three stations must have located the earthquake. Naturally, this takes a certain amount of time. In addition, telemetry and processing delay times must also be considered in order for the estimation to be as accurate as possible. According to our observations, the most significant time delays are caused by data packing at the station and unpacking at the processing center. In comparison, data processing time is negligible. For our research, we applied a fixed $2.5 \mathrm{~s}$ delay time; this accounts for transmission of the waveform data from each station to the processing center, processing time, and transmission of 

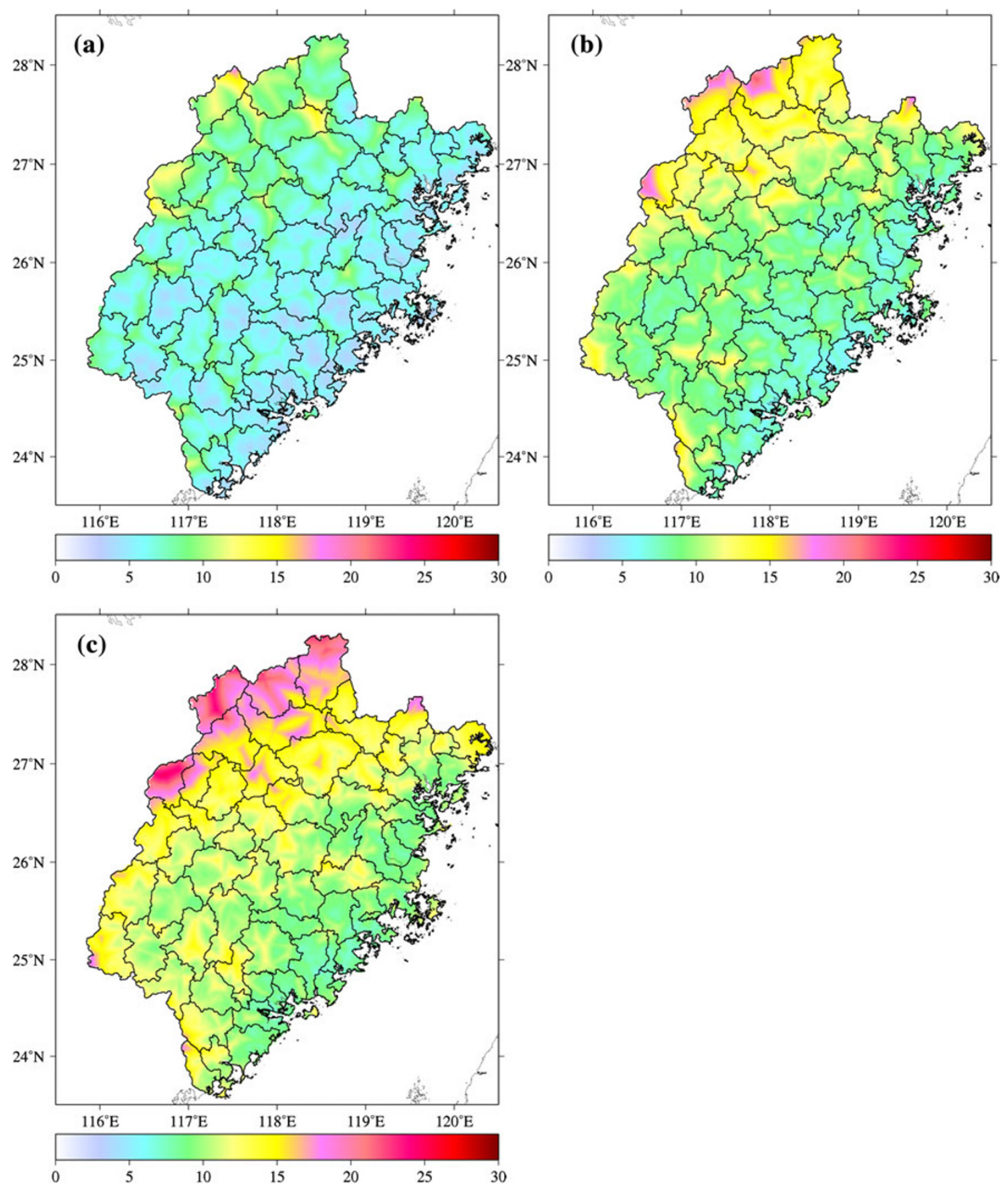

Fig. 4 Contour maps of the time needed for the release of EEW information post-earthquake (a-c are the times needed for the first, second, and third report, respectively)

the warning to the user community. The available warning time for a given city is different between early warning information release and the estimated time of peak ground shaking. For each earthquake, the seismic intensity that each city may suffer can be estimated by using seismic intensity attenuation relationships from previous studies. Here, we use seismic intensity attenuation relations provided by Wang et al. (2000) as follows:
$I=a+b M+c \log \left(R+R_{\mathrm{oa}}\right)+\varepsilon$,

where $a, b, c$ are fitting coefficients, $R_{\mathrm{oa}}$ is a parameter to reflect the seismic intensity saturation effect in the near field, and $\varepsilon$ is a random variable to express uncertainties during the fitting process. According to Wang et al. (2000), the values of each parameter are 5.019, 1.446, -4.136, 24.000 , and 0.517 , respectively. 
Table 4 Time needed for the release of each report

\begin{tabular}{|c|c|c|c|c|c|c|}
\hline & \multicolumn{2}{|c|}{ First report } & \multicolumn{2}{|c|}{ Second report } & \multicolumn{2}{|c|}{ Third report } \\
\hline & $3+1$ & $4+1$ & $7+2$ & $8+2$ & $10+3$ & $12+3$ \\
\hline \multicolumn{7}{|c|}{ Post-earthquake } \\
\hline Mean & 6.37 & 7.01 & 9.71 & 10.14 & 11.92 & 12.55 \\
\hline $95 \%$ & 10.12 & 11.84 & 14.55 & 15.31 & 18.53 & 19.27 \\
\hline \multicolumn{7}{|c|}{ Post-first station trigger } \\
\hline Mean & 3.71 & 4.37 & 7.06 & 7.49 & 9.27 & 9.90 \\
\hline $95 \%$ & 6.39 & 7.55 & 11.59 & 12.08 & 15.26 & 16.00 \\
\hline
\end{tabular}

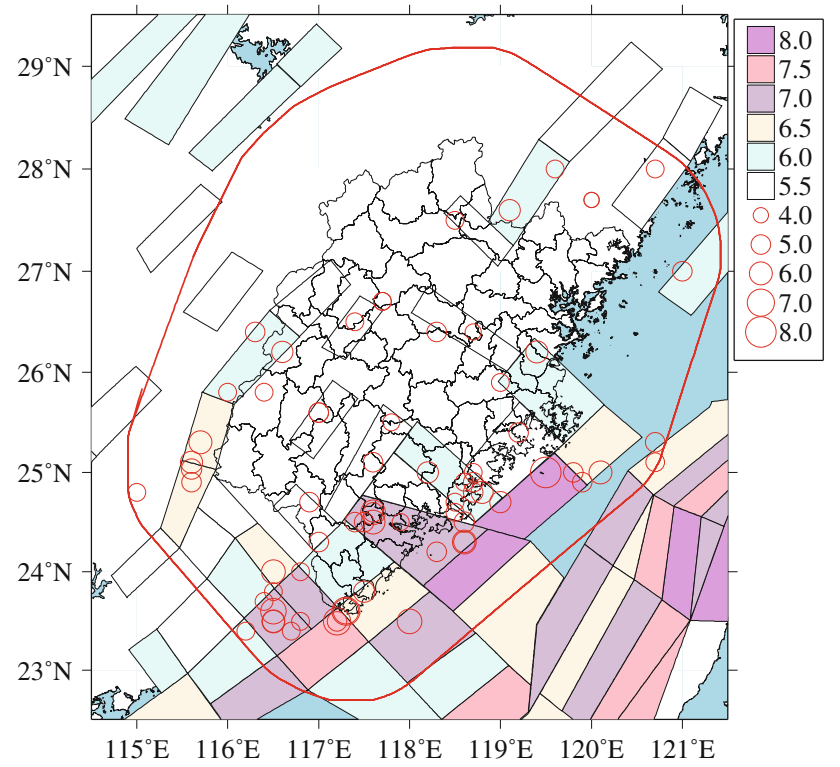

Fig. 5 Historical earthquake data and potential seismic source areas for the Fujian Province
Using methods outlined in Allen (2006), we can obtain the warning time probability density function (WTPDF) for each city. Taking Zhangzhou City as an example (Fig. 6), warning times vary from -10 to $150 \mathrm{~s}$, with $80 \mathrm{~s}$ being the most likely warning time. The highest seismic intensity that Zhangzhou is likely to experience is IX (Chinese intensity). Taking this into consideration, if the 1604 earthquake $\left(25.0^{\circ} \mathrm{N}, 119.5^{\circ} \mathrm{E}\right.$, magnitude is 8.0$)$ were to occur today, an early warning would be released $8.2 \mathrm{~s}$ after the earthquake and Zhangzhou City would have a $59.5 \mathrm{~s}$ advanced warning. Because the epicenter is located close to Zhangzhou, the seismic intensity caused by the earthquake is up to VII. In Table 5, we list the estimation results for 10 prefecture level cities in Fujian Province by applying the same method. It can be seen from this table that, most cities in the Fujian Province, would be given, at most, a $120 \mathrm{~s}$ window between the first report and the onset of seismic activity, and because these cities are located in different areas, they will experience different degrees of seismic intensity.

\section{Conclusions}

The EEW system is a new and effective way to mitigate the damage and loss of life associated with earthquakes. By the end of 2013, a prototype EEW system will be established based on 125 seismic monitoring stations distributed within the Fujian Province. In order to evaluate the efficiency of this system, we first establish an early warning release

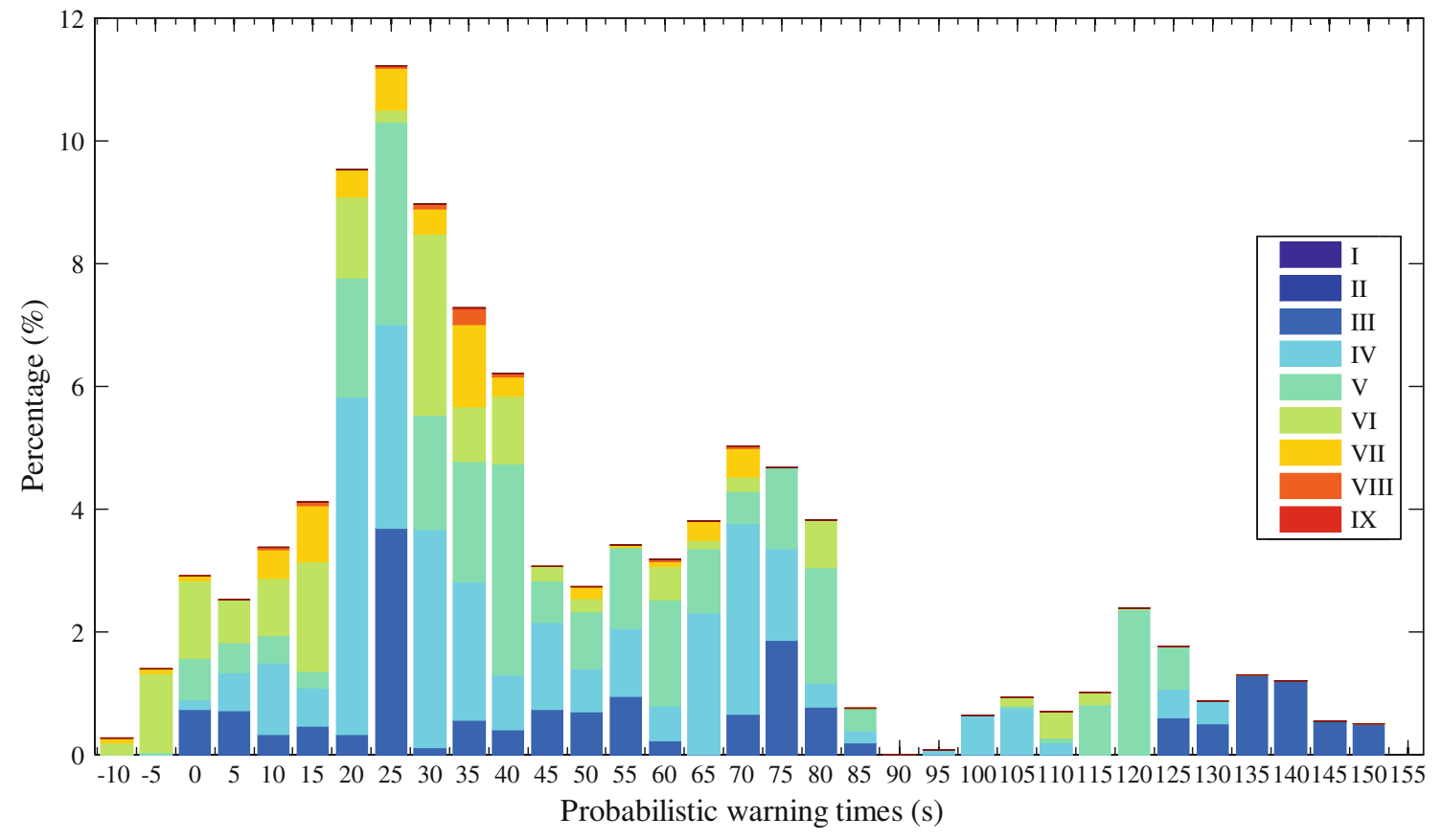

Fig. 6 Probable warning times for Zhangzhou City 
Table 5 Maximum seismic intensity and available warning times for 10 Fujian Province cities

\begin{tabular}{|c|c|c|c|c|c|c|c|}
\hline \multirow[t]{3}{*}{ City name } & \multirow{3}{*}{$\begin{array}{l}\text { Max likely } \\
\text { seismic } \\
\text { intensity }\end{array}$} & \multicolumn{6}{|c|}{ Maximum time available } \\
\hline & & \multicolumn{2}{|c|}{ First report } & \multicolumn{2}{|c|}{ Second report } & \multicolumn{2}{|c|}{ Third report } \\
\hline & & $3+1$ & $4+1$ & $7+2$ & $8+2$ & $10+3$ & $12+3$ \\
\hline Fuzhou & VIII & 141 & 140 & 136 & 133 & 131 & 130 \\
\hline Sanming & VII & 117 & 114 & 110 & 109 & 107 & 106 \\
\hline Ningde & VII & 162 & 159 & 156 & 154 & 152 & 149 \\
\hline Xiamen & IX & 151 & 149 & 141 & 140 & 138 & 138 \\
\hline Pingtan & IX & 149 & 148 & 141 & 140 & 137 & 137 \\
\hline Quanzhou & IX & 129 & 127 & 118 & 118 & 116 & 116 \\
\hline Zhangzhou & IX & 161 & 159 & 154 & 154 & 148 & 148 \\
\hline Putian & IX & 123 & 123 & 115 & 115 & 111 & 111 \\
\hline Nanping & VII & 128 & 124 & 122 & 120 & 118 & 115 \\
\hline Longyan & VII & 154 & 153 & 148 & 148 & 139 & 139 \\
\hline
\end{tabular}

scheme using statistical methods. We then obtain early warning release times. Using a combination of historical earthquake locations and the delineation of potential seismic source data, we calculate the WTPDF of 10 cities in the Fujian Province. Through these analyses, we are able to make a reliable evaluation of the potential efficiency of the EEW system in Fujian Province.

According to our statistical results, the time delay for data transmission in the Fujian Province is about $2 \mathrm{~s}$, whereas the processing time (including the detection of $\mathrm{P}$ wave arrivals, earthquake location and magnitude estimation, etc.) of the EEW system is negligible. By including time delays due to data transmission our evaluations reflect more accurate warning times for the Fujian region. It should be noted that our evaluation results are based mainly on theoretical assumptions and that our calculations assume that all monitoring stations are working properly. In reality, some stations may not function as predicted, which may have an effect on actual early warning times.

Nevertheless, according to our evaluation results, early warning signals could be drastically improved by improving facilities and targeted software to reduce the time latency during data transmission or by selecting more robust parameters to confirm an earthquake event more quickly and reliably. We predict that the EEW system will be one of the most important and effective tools to reduce earthquake hazards in the Fujian region.

Acknowledgments This study is supported by National Key Technology R\&D Program (2009BAK55B03).

\section{References}

Allen RM (2006) Probabilistic warning times for earthquake ground shaking in the San Francisco Bay area. Seismol Res Lett 77(3):371-376
Allen RM, Brown H, Hellweg M, Kireev A, Neuhauser D (2007) Realtime test of the ElarmS earthquake early warning methodology. J Geophys Res 112:B08311

Cooper JD (1968) Letter to editor. San Francisco Daily Evening Bulletin, 3 Nov 1968

Erdik M, Fahjan Y, Ozel O, Alcik H, Mert A, Gul M (2003) Istanbul earthquake rapid response and the early warning system. Bull Earthq Eng 1(1):157-163

Fan Y, Lin J, Hu R, Luo Z (1990) The development of travel timetable for near earthquake in south China. South China Seismol J 10(6):1-16 (in Chinese with English abstract)

Gilead W, Allen RM et al (2007) Toward earthquake early warning in northern California. J Geophys Res 112:B08311. doi:10.1029/ 2006JB004830,2007(1-19)

Horiuchi $S$ et al (2005) An automatic processing system for broadcasting earthquake alarms. BSSA 95(2):708-718. doi:10. $1785 / 0120030133$

Hsiao NC, Wu YM, Shin TC, Zhao L, Teng TL (2009) Development of an earthquake early warning system in Taiwan. Geophys Res Lett 36:L00B02. doi:10.1029/2008GL036596, http://www.jma. go.jp/jma/press/1103/29a/eew_hyouka.html

Iglesias A, Singh SK, Santoyo MA, Pacheco J, Ordaz M (2007) The seismic alert system for Mexico City: an evaluation of its performance and a strategy for its improvement. Bull Seismol Soc Am 97(5):1718-1729

Kamigaichi O (2004) JMA earthquake early warning. J Jpn Assoc Earthq Eng 4(3):134-137

Kamigaichi O, Saito M, Doi K et al (2009) Earthquake early warning in Japan: warning the general public and future prospects. Seismol Res Lett 80(5):717-726. doi:10.1785/gssrl. 80.5.717

Lin S, Chen W, Zheng S (2010) Statistical analysis of earthquake depth distribution in Fujian region. Earthquake 30(1):82-89 (in Chinese with English abstract)

Wang S, Yu Y, Gao A, Yan X (2000) Development of attenuation relations for ground motion in China (in Chinese). Earthq Res China 16(2):99-106

Wu YM, Teng TL (2002) A virtual subnetwork approach to earthquake early warning. Bull Seismol Soc Am 92(5):2008 2018

Zollo A, Iannaccone G et al (2009) Earthquake early warning system in southern Italy: methodologies and performance evaluation. Geophys Res Lett 36:L00B07. doi:10.1029/ 2008GL036689 
Zollo A, Iannaccone G, Manfredi G (2004) Development and experimentation of a prototype system for seismic early warning applications in Campania region (Southern Italy). In: Workshop on seismic early warning for European cities (abstracts), September 2004, Napoli, Italy, pp 23-25 